\title{
A Compact Inverted Y Slot Rectangular Microstrip Patch Antenna for Bluetooth Applications
}

\author{
Ramesh Kumar Verma, D.K. Srivastava \\ Department of Electronics \& Communication Engineering, Bundelkhand Institute of Engineering \& Technology, \\ Jhansi, UP, India
}

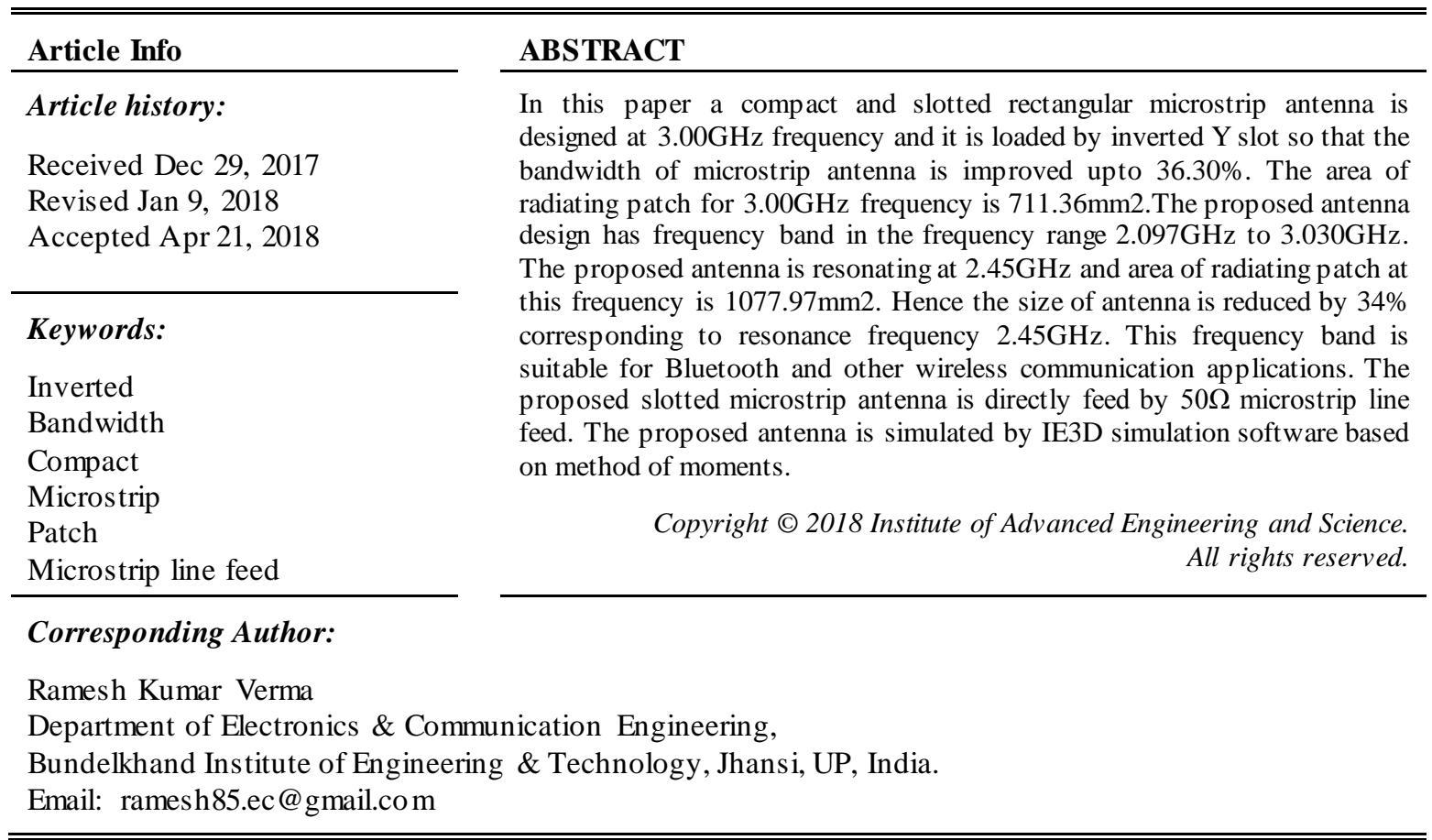

\section{INTRODUCTION}

The mobility of wireless communication devices has increased the demand of compact and low profile antennas with high gain and wideband operating frequencies. The microstrip patch antenna possesses many advantages such as low profile, light weight, small volume but the major drawback of microstrip antenna is its narrow bandwidth and lower gain. The size of antenna is extremely important for most wireless communication systems. The bandwidth of antenna decrease with the decrease of antenna size and this feature limits the design of compact antenna [1]. But it is required to have equivalent operation for decreased size antenna as compared with normal antenna [2]. A lot of methods have been proposed to obtain reduction in size of antenna like use of high permittivity dielectric substrates [3], Increase in electrical length of antenna by optimization of shape [4], Use of positioned notches on the patch antenna and various shapes of slots and slits lead to reduction in size of antenna [5]. These changes lead to increase surface current path. To lower resonant frequency of an antenna for a given surface area, current path is maximized within the area [6].

An 'inverted SHA' shaped defected ground plane has been used to increase the bandwidth of antenna by $5.3 \%$ with $16.01 \%$ reduction in the overall size of ground plane as compared to antenna without Defected [7]. The bandwidth of antenna has been improved by introducing double layered substrate and adding a metamaterial layer structure [8]. Slots and notch loaded microstrip patch antenna has been investigated for Wireless Communication at three distinct modes for dual-band operation [9]. A proximity coupled feed microstrip patch antenna with dual band has been designed using T slotted patch and dumbbell shape defected ground with $30.3 \%$ and $18.8 \%$ reduction in the overall area of the patch and the ground plane [10]. A monopole E-shaped compact patch antenna with enhanced bandwidth 71.35\% has been design for C- band applications with rectangular slots and defective ground structure [11]. An ultra-compact 
microstrip antenna array has been design by introducing interdigital resonator with mutual coupling between adjacent patches for wireless communication system operating in $2.4 \mathrm{GHz}$ frequency [12]. A radiation pattern reconfigurable compact microstrip patch antenna has been design and investigated with circle patch, radiation cells, coupling cells and MEMS switches to reduce the size of antenna by gradually decreasing resonance frequency from $4.27 \mathrm{GHz}$ to $3.76 \mathrm{GHz}$ [13]. A compact rectangular microstrip patch antenna has been designed with double patch and circular slots of different radius using probe feed excitation for RFID applications [14]. A broadband and compact stacked microstrip patch antenna has been developed using stacked configuration two parasitic patches stacked above the driven patch fed by shifted microstrip feed and a step transformer between feed and patch to achieve broadband coupling [15].

In the present work, the bandwidth of proposed design antenna is enhanced and size of antenna is reduced by loading inverted Y slot in the radiating patch which is directly feed by $50 \Omega$ microstrip line feed. The frequency band of proposed antenna lie between 2.097GHz to $3.030 \mathrm{GHz}$ which is suitable for Bluetooth and other communication applications [16-17]. The proposed antenna has been designed on glass epoxy substrate of thickness $1.6 \mathrm{~mm}$ with dielectric constant $\left(\varepsilon_{\mathrm{r}}=4.4\right)$ [18]. The substrate material has large influence in determining the size and bandwidth of an antenna. Increasing the dielectric constant decreases the size but lowers the bandwidth and efficiency of the antenna while decreasing the dielectric constant, increases the bandwidth but with an increase in size.

\section{ANTENNA DESIGN} by $[18,19]$

For designing of a rectangular microstrip patch antenna, the length and width are calculated

$$
\mathrm{W}=\frac{c}{2 f r} \sqrt{\frac{2}{\varepsilon r+1}}
$$

Where $\mathrm{c}$ is the velocity of light $\left(3 \times 10^{8} \mathrm{~m} / \mathrm{s}\right), \varepsilon_{\mathrm{r}}$ is the dielectric constant of substrate $(4.4), f_{\mathrm{r}}$ is the antenna design frequency $(3.00 \mathrm{GHz}), \mathrm{W}$ is the patch width, and the effective dielectric constant $\varepsilon_{\text {reff }}$ is given as $[18,19]$

$$
\varepsilon_{\text {reff }}=\frac{\varepsilon_{r}+1}{2}+\frac{\varepsilon_{r}-1}{2}\left(1+\frac{12 \mathrm{~h}}{\mathrm{w}}\right)^{-\frac{1}{2}}
$$

At $\mathrm{h}=1.6 \mathrm{~mm}$.

The extension length $\Delta \mathrm{L}$ is calculated by $[18,19]$

$$
\frac{\Delta L}{h}=0.412 \frac{\left(\varepsilon_{r e f f^{+0.3}}\right)\left(\frac{W}{h}+.264\right)}{\left(\varepsilon_{r e f f^{-}} .258\right)\left(\frac{W}{h}+0.8\right)}
$$

By using the above equation, we can calculate the value of actual length of the patch as $[18,19]$

$$
L=\frac{c}{2 f r \sqrt{\varepsilon r e f f}}-2 \Delta L
$$

The length and the width of the ground plane can be calculated a [18, 19]

$$
\begin{aligned}
& L_{g}=6 \mathrm{~h}+L \\
& W_{g}=6 \mathrm{~h}+W
\end{aligned}
$$

\section{ANTENNA DESIGN SPECIFICATIONS}

The proposed antenna design is shown in Figure 1. The design frequency of antenna is $3.00 \mathrm{GHz}$. The proposed antenna is designed by using glass epoxy substrate (FR-4) of a dielectric constant 4.4. Height of the dielectric substrate is $1.6 \mathrm{~mm}$ and loss tangent $(\tan \delta)$ is 0.02 . The calculated patch length and width are $23.4 \mathrm{~mm}$ and $30.4 \mathrm{~mm}$ respectively. The rectangular ground plane length and width are $33 \mathrm{~mm}$ and $40 \mathrm{~mm}$. The radiating patch of the antenna is feed through $50 \Omega$ microstrip line feed. All the antenna specifications are given in the Table 1 . Simulation work is done by using IE3D simulation software. 


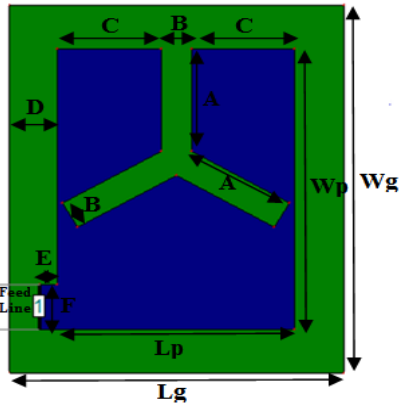

Figure 1. Geometry of proposed microstrip antenna

Table 1. Antenna design specifications

\begin{tabular}{clc}
\hline S. No. & \multicolumn{1}{c}{ Parameters } & Value \\
\hline 1. & Design frequency $\left(f_{\mathrm{r}}\right)$ & $3.00 \mathrm{GHz}$ \\
2. & Dielectric constant $\left(\varepsilon_{\mathrm{r}}\right)$ & 4.4 \\
3. & Substrate height $(\mathrm{h})$ & $1.6 \mathrm{~mm}$ \\
4. & Loss tangent $(\tan \delta)$ & 0.02 \\
5. & Patch width $(\mathrm{Wp})$ & $30.4 \mathrm{~mm}$ \\
6. & Patch length $(\mathrm{Lp})$ & $23.4 \mathrm{~mm}$ \\
7. & Ground plane width $(\mathrm{Wg})$ & $40 \mathrm{~mm}$ \\
8. & Ground plane length $(\mathrm{Lg})$ & $33 \mathrm{~mm}$ \\
\hline
\end{tabular}

\section{ANTENNA DESIGN PROCEDURE}

All the dimensions of proposed antenna has been calculated by using the Equations 1-6. The proposed microstrip patch antenna is loaded with inverted Y slot in the radiating patch. The ground plane of proposed antenna is starting from $(0,0)$ at lower left corner. The microstrip line feed of $50 \Omega$ is placed at lower left corner of the patch.

Initially, the design antenna is loaded with inverted Y slot in radiating patch and different antennas are design by varying the arm length and width of inverted Y slot. The simulation results of these antennas are given below as shown in Table 2 . The maximum bandwidth of antenna is $18.34 \%$ resonating at $3.054 \mathrm{GHz}$ with return loss $-17.42 \mathrm{~dB}$ when slot length and width $12 \mathrm{~mm}$ and $3 \mathrm{~mm}$ respectively.

Table 2. Conventional antenna result with different slot length and width

\begin{tabular}{ccccccc}
\hline $\begin{array}{c}\text { Slot Length } \\
(\mathrm{mm})\end{array}$ & $\begin{array}{c}\text { Slot width } \\
(\mathrm{mm})\end{array}$ & $\begin{array}{c}\text { Lower freq. } \\
(\mathrm{GHz})\end{array}$ & $\begin{array}{c}\text { Higher freq. } \\
(\mathrm{GHz})\end{array}$ & $\begin{array}{c}\text { Return loss } \\
(\mathrm{dB})\end{array}$ & $\begin{array}{c}\text { Resonance Freq. } \\
(\mathrm{GHz})\end{array}$ & $\begin{array}{c}\text { Bandwidth } \\
(\%)\end{array}$ \\
\hline 10 & 5 & 2.895 & 3.333 & -12.57 & 3.123 & 14.70 \\
11 & 5 & 2.829 & 3.330 & -13.7 & 3.096 & 16.36 \\
12 & 3 & 2.754 & 3.310 & -17.42 & 3.054 & 18.34 \\
11 & 3 & 2.781 & 3.312 & -15.89 & 3.066 & 17.43 \\
10 & 3 & 2.820 & 3.321 & -14.66 & 3.090 & 16.32 \\
\hline
\end{tabular}

Finally, the arm length and width of inverted Y slot are fixed at $12 \mathrm{~mm}$ and $3 \mathrm{~mm}$ respectively and length of feed strip is varying from $1.2 \mathrm{~mm}$ to $4.8 \mathrm{~mm}$ for enhancement of bandwidth. The maximum bandwidth has been achieved $36.30 \%$ when length of strip is $1.8 \mathrm{~mm}$ and width $4.8 \mathrm{~mm}$, show in Table 3 . The antenna is resonating at lower frequency $2.45 \mathrm{GHz}$ as compare to design frequency $3.00 \mathrm{GHz}$. The size of proposed antenna is reduced by $34 \%$. The geometry of proposed antenna is shown in Figure 1.

Table 3. Antenna design parameters

\begin{tabular}{ccc}
\hline S. No. & Parameters & Value $(\mathrm{mm})$ \\
\hline 1 & A & 12 \\
2 & B & 3 \\
3 & C & 10.2 \\
4 & D & 4.8 \\
5 & E & 1.8 \\
6 & F & 4.8 \\
\hline
\end{tabular}




\section{SIMULATION RESULT AND DISCUSSION}

In the present work the bandwidth of rectangular microstrip patch antenna is enhanced by slot loading. The performance of proposed microstrip patch antenna is analyzed by using IE3D simulation software at resonance frequency of $2.45 \mathrm{GHz}$. The simulation result of return loss is plotted for the range of frequency $1 \mathrm{GHz}$ to $4 \mathrm{GHz}$. The performance specifications return loss, VSWR, gain, efficiency, directivity and radiation pattern of proposed antenna is shown in the Figures 2 to 7 .

Figure 2 represents the comparis on between simulation and experimental results of the proposed antenna. The maximum fractional bandwidth of conventional antenna is $18.34 \%$ resonating at $3.054 \mathrm{GHz}$ with return loss $-17.42 \mathrm{~dB}$. The fractional bandwidth of proposed optimized antenna below $-10 \mathrm{~dB}$ is $36.30 \%$ which lies between $2.097 \mathrm{GHz}$ to $3.030 \mathrm{GHz}$ and antenna is resonating at $2.45 \mathrm{GHz}$ with return loss $-23.50 \mathrm{~dB}$. The Figure 2 also show the experimental bandwidth graph of proposed antenna and has impedance bandwidth of $29.82 \%$ in the frequency range $2.14 \mathrm{GHz}$ to $2.89 \mathrm{GHz}$ and resonating at $2.47 \mathrm{GHz}$ with return loss $-16.09 \mathrm{~dB}$. The simulation results and the experimental results vary due to fabrication defects.

The VSWR graph of the proposed antenna is shown in Figure 3. The VSWR of the antenna is lies between 1 to 2 in entire operating frequency band. The VSWR of the proposed antenna is 1.131 at resonance frequency.

Figure 4 represents the gain Vs frequency graph of the antenna. The maximum gain of the proposed antenna has been improved up to $3.309 \mathrm{~dB}$ at resonance frequency $2.45 \mathrm{GHz}$. Efficiency Vs frequency graph of antenna shown in Figure 5. The efficiency of proposed antenna is $99.62 \%$.at resonance frequency. Figure 6 represents the directivity Vs frequency graph of the antenna. The linear directivity of the proposed antenna is $3.326 \mathrm{~dB}$ at resonance frequency. As shown in Figure 7, the 2D Radiation pattern of antenna has 3dB beam width $(45.0964,150.871)$ deg. in E- plane direction. Image of experimental return loss Vs frequency graph measured by spectrum analyzer and antenna design hardware are shown in Figure 8 and Figure 9 respectively.

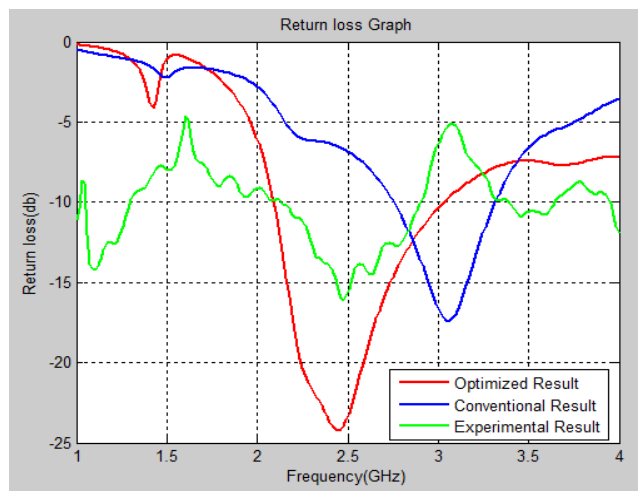

Figure 2. Comparis on between simulation and Experimental results

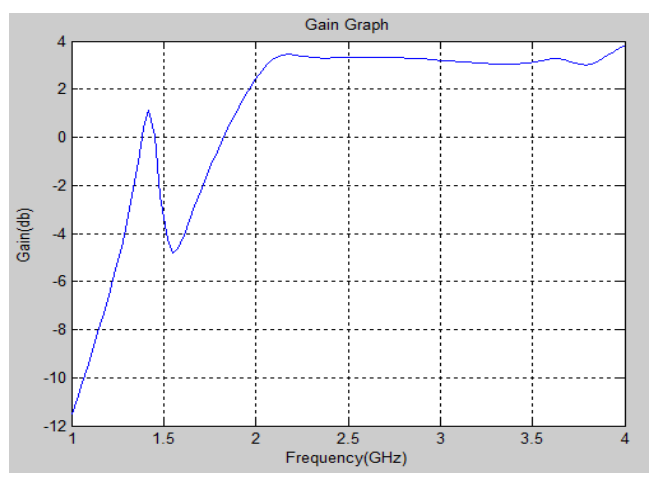

Figure 4. Gain Vs frequency graph

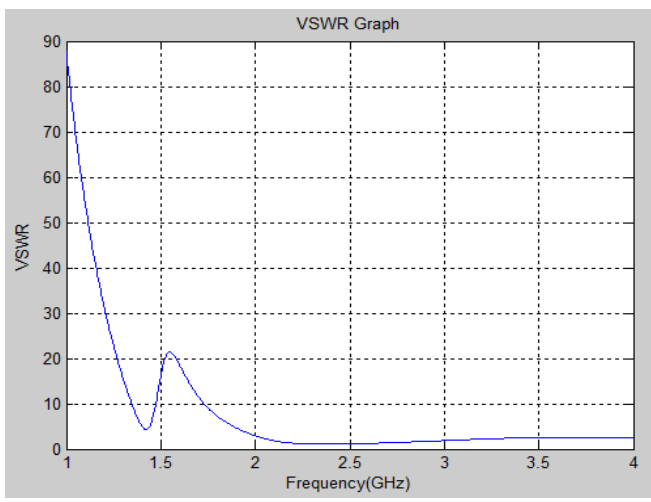

Figure 3. VSWR of proposed antenna

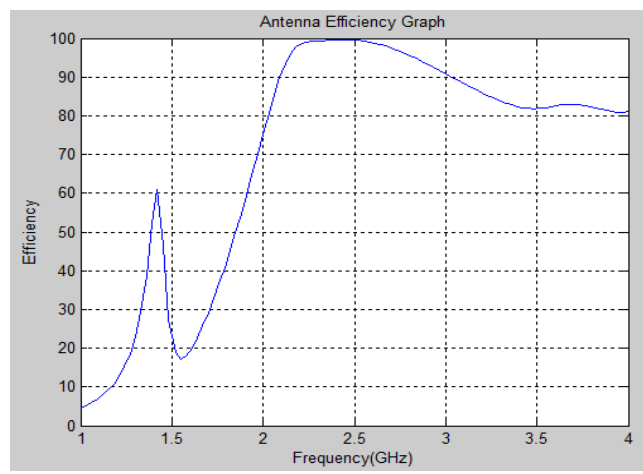

Figure 5. Efficiency Vs frequency graph 


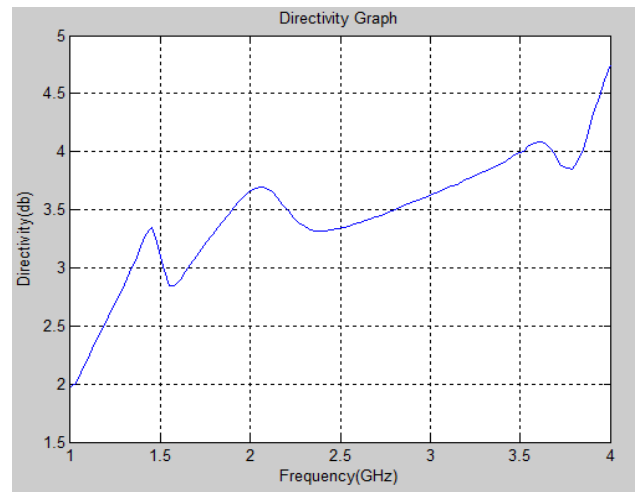

Figure 6. Directivity Vs frequency graph

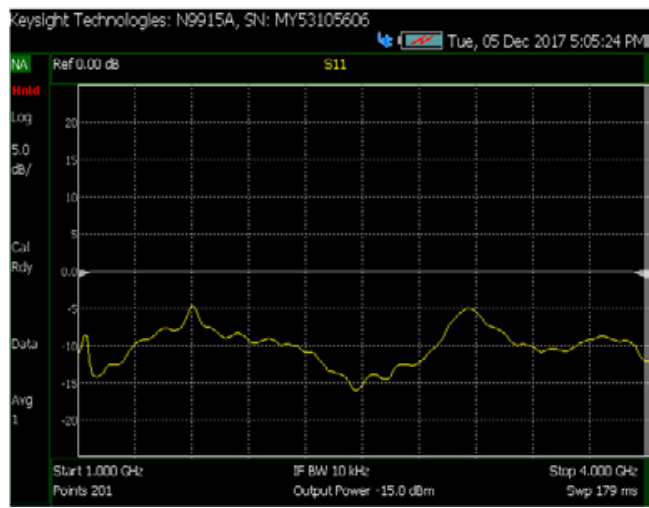

Figure 8. Experimental return loss Vs frequency graph

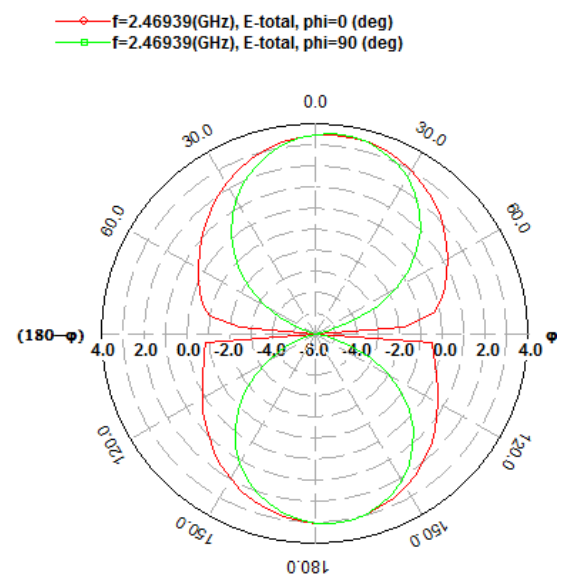

Figure 7. 2D Radiation pattern of antenna

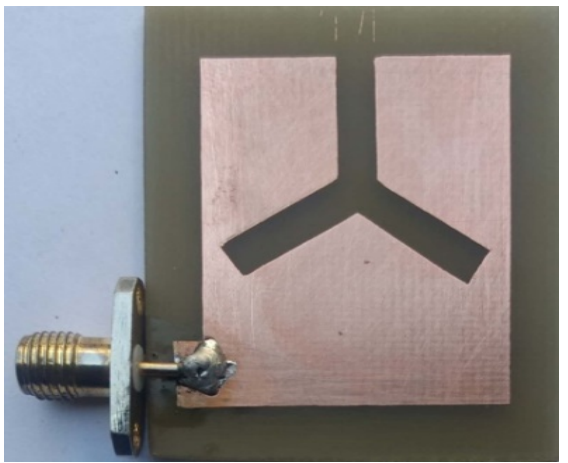

Figure 9. Hardware design of antenna

\section{CONCLUSION}

The impedance bandwidth of the traditional microstrip patch antenna is only a few percent (2\%-5\%) [20]. Therefore, it becomes very important to develop a new technique to enhance the bandwidth of the microstrip patch antenna and reduce the size of antenna. The proposed antenna design technique achieved much better results in terms of bandwidth enhancement as well as size reduction. Proposed antenna improved the fractional bandwidth from $18.34 \%$ to $36.30 \%$ with lower and upper frequencies as $2.097 \mathrm{GHz}$ and $3.030 \mathrm{GHz}$ respectively and antenna is resonating at $2.45 \mathrm{GHz}$. The size of antenna is reduced by $34 \%$. The proposed antenna has maximum antenna efficiency $99.62 \%$ and $3.309 \mathrm{~dB}$ gain. The VSWR of the antenna is lies between 1 to 2 in entire operating frequency band.

\section{REFERENCES}

[1] Chao Sun, Zhao Wu, Bowen Bai “A Novel Compact Wideband Patch Antenna for GNSS Application” IEEE Transactions on Antennas and Propagation , 2017, Vol-65, Issue-12,

[2] A. Kordzadeh and F. Hojat Kashani "A new reduced size Microstrip patch antenna with fractal shaped defects" Progress In Electromagnetics Research B, 2009, Vol-11, pp-29 37,

[3] B. N. Kiran Kumar, Vibha Rani Gupta and Nisha Gupta, "Reduced size, Wide Band Microstrip Patch Antenna for Wireless LAN Applications,” TechOnLine - Educational Resources for Electronics Engineers, June 05, 2008.

[4] Wang, H. Y. and M. J. Lancaster, “Aperture-coupled thin film superconducting meander antennas," IEEE Transaction on Antennas and Propagation, 1999, Vol-47, pp-829 836.

[5] S.Sarkar and P.P. Sarkar "Size Reduction of Rectangular Microstrip Patch Antenna using Slit Loaded Ground Plane” International Journal of Electronics \& Communication Technology (IJECT), June 2011, Vol-2,Issue-2

[6] Waterhouse, R., Printed Antennas for Wireless Communications, John Wiley \& Sons Inc, 2007.

[7] Dawit Fistum, Dilip Mali and Mohammed Ismail “ Bandwidth Enhancement of Rectangular Microstrip Patch Antenna using Defected Ground Structure” Indonesian Journal of Electrical Engineering and Computer Science, Vol. 3, No. 2, August 2016, pp. $428 \sim 434$ 
[8] V. Srinivasa Rao, K.V.V.S. Reddy and A.M. Prasad “ Bandwidth Enhancement of Metamaterial loaded Microstrip Antenna using Double Layered Substrate” Indonesian Journal of Electrical Engineering and Computer Science, Vol. 5, No. 3, March 2017, pp. $661 \sim 665$.

[9] Ashish Singh, Kamakshi, Mohd. Aneesh and J.A. Ansari "Slots and Notches Loaded Microstrip Patch Antenna for Wireless Communication” TELKOMNIKA (Telecommunication, Computing, Electronics and Control), Vol. 13, No. 3, March 2015, pp. $584 \sim 594$

[10] Dawit Fitsum, Dilip Mali and Mohammed Ismail "Dual-Band Proximity Coupled Feed Microstrip Patch Antenna with ' $\mathrm{T}$ ' Slot on the Radiating Patch and 'Dumbbell' Shaped Defected Ground Structure” Indonesian Journal of Electrical Engineering and Computer Science, Vol-3, No.-2, August 2016, pp-435 440.

[11] Anusha U, and Lethakumary B “ A Compact Microstrip Antenna for C Band Applications” IOSR Journal of Electronics and Communication Engineering (IOSR-JECE), 2017, pp- 12 15

[12] Wei Qiao, Xi Gao, Xing Yang Yu, Si Min Li, Yan Nan Jiang and Hui Feng Ma "Ultra-Compact Microstrip Antenna Array and Miniaturized Feeding Network” Progress In Electromagnetics Research C, Vol-71, 2017, pp-111 122

[13] Wei-Dong MA, Guang-Ming WANG, Ya-Wei WANG and Bin-Feng ZONG "Compact Microstrip Antenna with Pattern-Reconfigurable Characteristic” Radioengineering, VOL. 26, NO. 3, September 2017, pp-662 667.

[14] Ranjeet Singh and Simranjeet Singh Tiwana “ Design and Performance of a Compact Microstrip Patch Antenna using Circular slots And Stub for RFID Applications” SSRG International Journal of Electronics and Communication Engineering (SSRG-IJECE), Vol- 4 Issue-8 - August 2017.

[15] Ankita Katyal and Ananjan Basu "Compact and Broadband Stacked Microstrip Patch Antenna for Target Scanning Applications” 1536-1225 (c) 2016 IEEE.

[16] Chuan-Ling Hu, Chang-Fa Yang and Shun-Tian Lin, "A Compact Inverted-F Antenna to be Embedded in Ultrathin Laptop Computer for LTE/WWAN/WI-MAX/WLAN Applications”, IEEE Transaction on Antennas and Propagation, 2011,

[17] Avisankar Roy and Sunandan Bhunia, "Compact Broad Band Dual Frequency Slot Loaded Microslot Patch antenna with Defecting Ground Plane for WI-MAX and WLAN”, International Journal of Soft Computing \& Engineering, 2012, Vol-1, Issue-6.

[18] K. V. Rop, D. B. O. Konditi, H. A. Ouma and S. M. Musyoki, "Parameter optimization in design of a rectangular microstrip patch antenna using adaptive neuro-fuzzy inference system technique", International Journal on Technical and Physical Problems of Engineering, 2012, Vol-4, pp-16 23

[19] Constantine A. Balanis, “Antenna theory, Analysis and Design”, John Wiley \& Sons, Inc Hoboken, New Jersey, 2005.

[20] Pozar, D.M, “Microstrip antennas”, proceeding of the IEEE, January 1992, Vol-40

[21] IE3D simulation software, Zeland. 